\title{
Car ownership and the Labor Market of Ethnic Minorities
}

\author{
Pieter A. Gautier* $\quad$ Yves Zenou ${ }^{\dagger}$
}

January 29, 2009

\begin{abstract}
We show how small initial wealth differences between low skilled black and white workers can generate large differences in their labor-market outcomes. This even occurs in the absence of a taste for discrimination against blacks or exogenous differences in the distance to jobs. Because of the initial wealth difference, blacks cannot afford cars while whites can. Car ownership allows whites to reach more jobs per unit of time and this gives them a better bargaining position. As a result, in equilibrium, blacks end up with both higher unemployment rates and lower wages than whites. Furthermore, it takes more time for blacks to reach their jobs even though they travel less miles. Those predictions are consistent with the data. Better access to capital markets or better public transportation will reduce the differences in labor market outcomes.
\end{abstract}

Key words: Transportation mismatch, job search, spatial labor markets, multiple job centers, ethnic minorities.

JEL Classification: D83, J15, J64, R1.

*VU University Amsterdam, Tinbergen Institute and CEPR. E-mail: pgautier@feweb.vu.nl.

${ }^{\dagger}$ Stockholm University and Research Institute of Industrial Economics, Sweden. E-mail: yves.zenou@ne.su.se. Also affilated with GAINS and CEPR. 
Urban transit systems in most American cities ... have become a genuine civil rights issue-and a valid one-because the layout of rapid-transit systems determines the accessibility of jobs to the Black community. If transportation systems in American cities could be laid out so as to provide an opportunity for poor people to get meaningful employment, then they could begin to move into the mainstream of American life. A good example of this problem is my home city of Atlanta, where the rapid-transit system has been laid out for the convenience of the white upper-middle-class suburbanites who commute to their jobs downtown. The system has virtually no consideration for connecting the poor people with their jobs.

Martin Luther King, Jr. (1986, pp. 325-326)

\section{Introduction}

Empirical evidence for the United States suggests that, relative to white workers, black workers: $(i)$ are less likely to own a car, $(i i)$ experience higher unemployment rates and longer unemployment spells, (iii) earn lower wages, (iv) spend more time commuting to work, $(v)$ travel less miles to go to their jobs, (vi) search for jobs in a smaller area. See e.g. Holzer et al. (1994) and Raphael and Stoll (2001). Many papers, some of which are discussed below, offer explanations for a subset of those facts. The aim of this paper is to construct a model that can simultaneously explain all of them.

Most of the literature has focussed on why blacks experience higher unemployment rates and earn lower wages than whites. Different answers have been given to those crucial questions but the recent debate, especially in the United States, has been focussing on the role of segregation in explaining these unemployment rate differences. The spatial mismatch hypothesis, first formulated by Kain (1968), states that, residing in urban segregated areas distant from and poorly connected to major centers of employment growth, black workers face strong geographic barriers to finding and keeping well-paid jobs. In the U.S. context, where jobs have been decentralized and blacks have stayed in the central part of cities, the main conclusion of the spatial mismatch hypothesis is to put forward the distance to jobs as the main culprit for the high unemployment rates among blacks.

Since the study of Kain, dozens of empirical studies have been carried out trying to test this hypothesis. The usual approach is to relate a measure of labor-market outcomes, based on either individual or aggregate data, to another measure of job access, typically some index that captures the distance from residences to centers of employment. The bulk of the evidence suggests that bad job access indeed worsens labor-market outcomes, confirming the spatial mismatch hypothesis (for literature surveys, see Ihlanfeldt and Sjoquist, 1998; 
Gobillon et al., 2005; Ihlanfeldt, 2006; Zenou, 2009).

However, spatial mismatch can not explain all the facts described above. In particular, it cannot explain that black workers travel less miles to work but that it takes more time for them. It is therefore important to introduce mode choices in the explanation. ${ }^{1}$ Some researchers have even put forward the idea of an automobile or transportation mismatch rather than a spatial mismatch to understand the adverse labor-market outcomes of black workers in the United States (see, in particular, Taylor and Ong, 1995). Since most blacks use mass transit, ${ }^{2}$ the choice of transportation is indeed crucial, in particular, in large American metropolitan areas where public transportation is not that good (see e.g. Pugh, 1998). ${ }^{3}$ Indeed, mass transit is a much slower transport mean than private cars in the United States not only because buses are slower but also because of the unreliability of the transit system that causes workers to frequently miss transfers and of the fact that many areas are difficult to reach by public transport. In the United States, in 2000, the average commuting time by public transit was about twice as high as by car (47.7 versus 24.1 minutes; see Kawabata and Shen, 2007). As a result, some jobs will be turned down by blacks, not because these jobs are too far away but because they are difficult to access. So our main point here is that car

\footnotetext{
${ }^{1}$ The theoretical models that explicitly model the spatial aspects of the labor market (see, in particular, Coulson et al., 2001; Brueckner and Zenou, 2003; Smith and Zenou, 2003; Sato, 2001, 2004) have mainly tried to explain the spatial mismatch hypothesis thus focussing on distance to jobs as the main culprit for the adverse labor-market outcomes of black workers (for an overview, see Zenou, 2009). There are also some search models that study how workers determine their maximum area of search (see e.g. Schwartz, 1976 or Seater, 1979) but neither mode choice nor race are introduced in their models. To the best of our knowledge, our paper is the first that develops a search-matching model where mode-choice decisions affect labor-market outcomes of black and white workers.

${ }^{2}$ Using data drawn from the 1995 Nationwide Personal Transportation Survey, Raphael and Stoll (2001) show that, in the US, 5.4 percent of white households have no automobile while 24 and 12 percent of respectively the black and Latino households do not own a car. Even more striking is that they show that respectively 64 and 46 percent of black and Latino households have only one or zero cars whereas this number was 36 percent for white households. In Great-Britain, using the 1991 Census data, Owen and Green (2000) show that people from minority ethnic groups are more than twice as likely as white people to depend on public transport for commuting journeys (33.2 versus 13.7 percent), with nearly three-fifths of Black-African workers using public transport to go to work. Furthermore, 73.6 percent of the whites use a private vehicle while this number is only 56.4 percent for ethnic minorities (and 39.6 percent for Black-African workers). Using the Labour Force Survey for England, Patacchini and Zenou (2005) find similar results.

${ }^{3}$ In U.S. Metropolitan Statistical Areas, the lack of good public transportation is a real problem. For instance, the New York Times of May 26, 1998, was telling the story of Dorothy Johnson, a Detroit inner-city black female resident who had to commute to an evening job as a cleaning lady in a suburban office. By using public transportation, it took her two hours whereas, if she could afford a car, the commute would have taken only 25 minutes.
} 
access rather than distance to jobs that make black workers experience high unemployment rates. In particular, because of urban sprawl and increasing job creation in the suburbs in the United States (Brueckner, 2000, 2001; Glaeser and Kahn, 2001; Glaeser and Shapiro, 2003; Glaeser and Kahn, 2004; Nechyba and Walsh, 2004), black families, who mostly reside in the central part of cities, are more and more isolated from jobs that potentially match their skills (Wassmer, 2008). ${ }^{4}$ Given this sprawling, access to good transportation enables residents to conduct geographically broader job-search, accept offers further away from home, improve work attendance, and keep the commute burden to a reasonable level. In other words, in the highly auto-oriented US metropolitan areas, the number of accessible job opportunities is considerably lower for public transit users than for car users (Hess, 2005; Shen, 1998). It is then reasonable to hypothesize that car ownership is an important factor in improving the employment status of welfare recipients. In our model, we show that not having access to cars has a dramatic impact on blacks' labor market outcomes.

To be more precise, firms have no taste for discrimination and ex ante blacks and whites are located at the same distance to jobs. Apart from the color of their skin, the only difference between black and whites is an initial wealth difference. We show that this forces black workers to choose public transportation while whites can afford cars. Since the set of jobs that can be reached by car is larger than the set that can be reached by public transportation, whites find jobs faster and experience shorter unemployment spells. Living far away from one's job could in principle signal car ownership but not if home location is either unobservable or not verifiable (i.e. workers can always provide fake addresses). Employers do observe the worker's type (black or white) and since whites have on average a better bargaining position, they earn higher wages. This is a standard statistical discrimination argument (see e.g. Arrow, 1973 or Phelps, 1972).

So, the main idea behind our results is that the set of available jobs for black workers who mainly use public transportation is smaller than for whites who can travel much faster. In other words, blacks will refuse some jobs that are not accessible by public transportation while they would have accepted them if they had a car. ${ }^{5}$ Zax and Kain (1996) have illustrated

\footnotetext{
${ }^{4}$ In the United States, between 1970 and 1990, the ratio of jobs to workers in the central city declined from 1.2 to 1 for whites, while for blacks the ratio declined to 0.7 (O'Regan and Quigley, 1998). This indicates that a sizable fraction of black workers are reverse commuters, that is, they live in central cities and work in the suburban ring.

${ }^{5}$ Using data from the European Community Household Panel (ECHP) for 1994-2001 and for a sample of currently unemployed job seekers, Rupert et al. (2009) report that $14.7 \%$ of job offers were turned down due to commute distance. They also indicate that the impact of commute distance is roughly a third lower than the impact of the wage rate when the job acceptance decision has to be made.
} 
this issue by studying an interesting "natural experiment" (the case of a large firm in the service industry that relocated from the center of Detroit to the suburb Dearborn in 1974). ${ }^{6}$ Among workers whose commuting time was increased, black workers were over-represented, and not all of them could follow the firm. This had two consequences. First, segregation forced some blacks to quit their jobs. Second, the share of black workers applying for jobs to the firm drastically decreased ( $53 \%$ to $25 \%$ in 5 years before and after the relocation), and the share of black workers in hires also fell from $39 \%$ to $27 \% .^{7}$ This highlights the fact that black workers may refuse jobs that involve too long commutes, not necessarily because they are far away in terms of miles traveled but because they are not reachable by public transportation.

The paper is organized as follows. In section 2, we discuss the model and its assumptions. Section 3 characterizes the equilibrium and derives the sources of differences in labor market outcomes between blacks and whites. Section 4 discusses some policy implications of the model.

\section{The model}

\subsection{Labor market flows}

We consider a continuum of workers and firms. The total mass of workers is normalized to one. A fraction $(1-p)$ of the workers are blacks and a fraction $p$ are whites. Both are assumed to be identical apart from the color of their skin and a difference in initial wealth. We assume that whites have higher wealth flows than blacks, i.e. $\Omega_{W}>\Omega_{B}$, where the subscript $k=B, W$ denotes the race of an individual. Differences in initial wealth can be justified on the ground that blacks and whites did not experience the same history in the United States. As we will see below, $\Omega_{W}$ and $\Omega_{B}$ can also be interpreted in terms of access to the capital market.

Following Salop (1979), we model workers' and firms' heterogeneity by means of a circle along which workers are uniformly distributed over its circumference $C$ of length 1.8 This is the geographical space and we denote by $0 \leq x_{i j} \leq 1 / 2$ the geographical distance between a worker located in $i$ and a firm located in $j .{ }^{9}$ It is assumed that workers are unable to change

\footnotetext{
${ }^{6}$ See also Fernandez (1994) for a similar "natural experiment".

${ }^{7}$ For a survey on these issues, see Fernandez and Su (2004).

${ }^{8}$ See, among others, Marimon and Zilibotti (1999), Hamilton et al. (2000), Brueckner et al. (2002), Gautier et al. (2008) for a similar way of modelling heterogeneity.

${ }^{9}$ Because it is a circle of lenght 1 where distance is measured on both sides, the maximum distance between
} 
their residential location. One way to justify this assumption is that homes are less mobile than jobs (Manning, 2003).

Time is continuous and workers live forever. At each moment in time, a worker can be either employed or unemployed. All unemployed workers search for a job and we assume that there is no on-the-job search. Similarly, at each moment in time, a firm can have either a filled position or an open vacancy. Let $u_{k}(i)$ be the number of type- $k$ unemployed workers, $k=\{B, W\}$, (or equivalently the unemployment rate of type $k$-workers) at location $i$ and $v(j)$ the number of vacancies (or equivalently the vacancy rate) at location $j$.

The uniform distribution of workers over the circle implies that $u_{k}(i)=u_{k}, \forall i \in C$. It is easy to show (see Lemma 1 of Marimon and Zilibotti, 1999) that, in this case, there exists a stationary equilibrium with a uniform distribution of vacancies at all locations, i.e. $v(j)=v$, for all $j \in C$. Gautier et al. (2006) show that this distribution must be unique. The intuition for this result is that if this distribution is non-uniform than there exists a profitable deviation for firms in non-dense areas (in terms of workers), namely to move to a denser area.

In standard search-matching models, individuals choose reservation wages by comparing the values of employment and unemployment and equating them at the margin. ${ }^{10}$ In the present model, we include space into a search-matching model and this creates a new decision for job seekers and firms. Workers must now also decide how large the area of search is and firms where to locate, given the location of workers.

To be more precise, search is random and the number of contacts between workers and firms is given by:

$$
M\left(u_{B}+u_{W}, v\right) \equiv M .
$$

As usual (Pissarides, 2000), $M($.$) is assumed to be increasing in its arguments, concave and$ exhibits constant returns to scale. Let $\theta=v /\left(u_{B}+u_{W}\right)$ be labor-market tightness. The contact rate for type $k$ workers with a vacancy is given by:

$$
\frac{M}{u_{B}+u_{W}} \equiv m(\theta)
$$

The contact rate of a vacancy with a type $-k$ worker is given by:

$$
\frac{M}{v} \frac{u_{k}}{u_{B}+u_{W}}=\frac{u_{k}}{u_{B}+u_{W}} \frac{m(\theta)}{\theta}
$$

By using the properties of the matching function, it is easy to see that

$$
m^{\prime}(\theta)>0 \text { and } \frac{\partial[m(\theta) / \theta]}{\partial \theta}<0
$$

a firm and a worker is $1 / 2$.

${ }^{10}$ See e.g. Diamond (1982), Mortensen (1982), Pissarides (2000). 
since more vacancies increase the rate at which workers find a job and decrease the rate at which firms fill a vacancy. We also assume the standard Inada conditions on $M($.$) , which$ ensure that $\lim _{\theta \rightarrow+\infty} m(\theta)=\lim _{\theta \rightarrow 0} m(\theta) / \theta=+\infty, \lim _{\theta \rightarrow 0} m(\theta)=\lim _{\theta \rightarrow+\infty} m(\theta) / \theta=0$.

We can now model precisely the matching process between a worker of type $k$ and a firm. For a worker, a match will occur if and only if:

$$
\text { Match }_{u_{k} \rightarrow v}=\underbrace{m(\theta)}_{\text {Random contact }} \times \underbrace{2 \widehat{x}_{k}}_{\text {Probability contact is acceptable }}
$$

A match is the product of a contact rate and an acceptation rule. Independently of race, job contacts arrive randomly to workers at rate $m(\theta)$ (for example, workers read newspapers and observe advertisements). For a given job contact, workers must decide to apply or not to this job, depending on its location. This second stage depends on the chosen transport mode. Observe that the term $\widehat{x}_{k}$ is multiplied by 2 because each worker considers the distance to jobs from both sides of his/her location.

The rate at which vacancies match with a type- $k$ worker is given by:

$$
\operatorname{Match}_{v \rightarrow u_{k}}=\underbrace{\frac{u_{k}}{u_{B}+u_{W}} \frac{m(\theta)}{\theta}}_{\text {Random contact }} \times \underbrace{2 \widehat{x}_{k}}_{\text {Probability contact is acceptable }} .
$$

First, firms advertise their jobs. They are then contacted by workers and will offer a job only to type- $k$ workers located within a distance $x \leq \widehat{x}_{k}$.

We assume that jobs are destroyed at an exogenous rate $\delta$ so the steady state conditions for type $k$ workers are given by:

$$
2 m(\theta) \widehat{x}_{k} u_{k}=\delta e_{k},
$$

where $e_{k}$ is the employment level (or rate) of workers of type $k$. Finally, normalizing the labor force to one implies that:

$$
u_{B}+u_{W}+e_{B}+e_{W}=1 .
$$

From, (3), (4) and the definition of $p$ we can derive the following steady state relationship:

$$
2 m(\theta) \widehat{x}_{k} u_{k}=\delta\left(p-u_{k}\right),
$$

so that:

$$
\begin{aligned}
u_{B} & =\frac{\delta(1-p)}{\delta+2 \widehat{x}_{B} m(\theta)} \\
u_{W} & =\frac{\delta p}{\delta+2 \widehat{x}_{W} m(\theta)} .
\end{aligned}
$$




\subsection{Asset values of the various labor market states}

Contrary to the standard assumption in urban economics where only one employment center prevails (see e.g. Fujita, 1989; Zenou, 2009), here there is a continuum of job locations and jobs are uniformly distributed around the circle. Over their lifetime, workers change jobs but not their residential location so that distance to jobs changes stochastically over time. As a result, on average, over their lifetime, the physical distance to jobs is the same for all workers of type $k^{11}$

Let $\Omega_{k}$ be the per-period wealth flow that a worker has access to, either through family funds or through the capital market. We assume that $\Omega_{W}>\Omega_{B}$, capturing the idea that black workers have less initial wealth than whites ${ }^{12}$ and/or that they have a more difficult access to the capital market. ${ }^{13}$ All unemployed workers receive unemployment benefits $b$ (this can also be interpreted as home production) and pay a flow cost $f_{k}$ of using transportation mode $k .^{14}$ The cost $f_{k}$ includes insurance, petrol, lease contract and maintenance for car owners (i.e. $f_{W}$ ) and a monthly public transportation card for mass transit users (i.e. $f_{B}$ ). Workers can only choose one transportation mode, either for commuting to work (when they are employed) or for job search and shopping (when they are unemployed). So for both car owners and public transport users, the flow cost $f_{k}$ will be the same independently of their employment status. All workers are risk neutral. Thus, an unemployed worker of type $k$ obtains instantaneous utility $\Omega_{k}+b-f_{k}$, while an employed worker, earning $w_{k}$ and working at a geographical distance $x$, obtains instantaneous utility $\Omega_{k}+w_{k}-T_{k}(x)$, where $T_{k}(x)$ is total commuting cost at distance $x$. As we will see below, wages do not depend on $x$ because the residential location of each worker is not directly observable.

Let $\tau$ be a positive coefficient and $t_{k}(x)$ the time it takes to commute to jobs when residing

\footnotetext{
${ }^{11}$ This is why we do not introduce land rent in this model since it would not depend on distance to jobs and will have the same value at each location. Therefore, it will not affect the results of the model.

${ }^{12}$ This is a well-documented fact (see, e.g. Barsky et al., 2002). Because wealth is usually transferred from generation to generation, the large current racial wealth gap between blacks and whites may be a function of past racial differences in economic conditions and opportunities (due to the very specific history of African Americans, that is slavery).

${ }^{13}$ It is well-documented that, in the US, black families pay higher interest rates on the loans used to purchase housing (Charles and Hurst, 2002; Mayer et al., 2008) and vehicles (Cohen, 2007; Charles et al., 2008). For example, Cohen (2007) finds that roughly $43 \%$ to $72 \%$ of blacks are charged interest rate "markups" while only $22 \%$ to $47 \%$ of whites face these higher prices for vehicle financing. Charles et al. (2008) show that the interest rates for vehicle loans paid by blacks are, on average, a full 100 basis points higher: $10.6 \%$ versus $9.6 \%$.

${ }^{14}$ Because it will be shown below that there is a one-to-one correspondence between race and transport mode, subscript $k$ denotes both race and transport mode.
} 
at distance $x$. This implies $\tau w_{k} t_{k}(x)$ represents the total time cost for a person residing at a distance $x$ from her job. ${ }^{15}$ Then, $T_{k}(x)$ is given by:

$$
T_{k}(x)=f_{k}+\tau w_{k} t_{k}(x)
$$

We show below (in Section 3.4) that, because $\Omega_{W}>\Omega_{B}$, there exists an equilibrium where even the most wealthy black workers (the ones who have been employed most of the time) cannot afford a car while the least wealthy whites (those who have experienced the longest unemployment spells) can. So, from now on, when we talk about transportation issues, $k=B$ implies public transportation while $k=W$ implies cars. As a result, $f_{k}$ is the nontime cost of transportation. We assume that switching transport mode is sufficiently costly so once a transportation mode decision is made, it is always optimal to stick to it even when one becomes unemployed (see Section 3.4). Naturally, we assume that $f_{W}>f_{B}$, it is more costly to have a car than to use public transportation. As usual in this type of model, the wage represents the opportunity cost of time. Let $\mu_{k}$ be the (average) speed of a trip to work for a worker of type $k$. Then,

$$
t_{k}(x)=\frac{x}{\mu_{k}} .
$$

We assume that $\mu_{W}>\mu_{B}$. Indeed, $\mu_{k}$ not only measures how fast the transport mode is but also the "smoothness" of the transportation system. As stated in the introduction, it is well-documented that in large U.S. cities, there is a lack of good public transportation.

In this context, distance to jobs can be measured in terms of either physical distance $x$ (i.e. number of miles) or time distance $t_{k}(x)$ (i.e. hours). In other words, two workers using different transport modes, will not reach the same physical distance during the same time.

Let $U_{k}$ be the expected discounted lifetime utility of an unemployed worker ${ }^{16}$ of type $k$ and $E_{k}\left(x, w_{k}\right)$ be the expected discounted lifetime utility of an employed worker of type $k$ living at a distance $x$ from her job and earning a wage $w_{k}$. Then:

$$
r U_{k}=\Omega_{k}+b-f_{k}+m(\theta)\left[2 \int_{0}^{\widehat{x}_{k}}\left[E_{k}\left(x, w_{k}\right)-U_{k}\right] d x\right] .
$$

\footnotetext{
${ }^{15}$ This is the common way of modelling transport cost in the transport mode choice literature; see for example LeRoy and Sonstelie (1983) and Sasaki (1990). For simplicity and without loss of generality, we have omitted in (7) the variable part of the commuting cost (i.e. the pecuniary commuting cost). Observe however that, in a more general model, the link between commuting costs and the wage paid is achieved through a labor-leisure choice, which implies that a unit of commuting time is valued at the wage rate (see, for example, Fujita, 1989, Chapter 2). However, such a model is cumbersome to analyze, and it is likely not to yield additional insights beyond those available from our simpler approach, which is consistent with the empirical literature that shows that the time cost of commuting increases with the wage (see, e.g. Small, 1992, and Glaeser et al., 2008).

${ }^{16}$ To save on notation we leave out subscript $i$ when there is no possibility of confusion.
} 
where $r \in(0,1)$ is the discount rate, and $\widehat{x}_{k}$ is the maximum geographical distance a worker is willing to travel (beyond $\widehat{x}_{k}$ all jobs will be turned down by the unemployed workers). First observe that $U_{k}$ does not depend on $x$ because search is random (i.e. workers just read newspaper advertisements) so firms cannot sort workers by locations. When a worker of type $k$ is unemployed today, her instantaneous utility is $\Omega_{k}+b-f_{k}$. She meets vacancies at rate $m_{k}(\theta)$ and a fraction $2 \widehat{x}_{k}$ of the vacancies are located at an acceptable distance from the worker. All jobs beyond distance $\widehat{x}_{k}$ will be turned down. When a worker accepts a job offer at distance $x$ from her residential location, she obtains a wealth increase of $E_{k}\left(x, w_{k}\right)-U_{k}$. The asset value for an employed worker who is employed at distance $x$ from her home is given by: ${ }^{17}$

$$
r E_{k}\left(x, w_{k}\right)=\Omega_{k}+w_{k}\left(1-\tau \frac{x}{\mu_{k}}\right)-f_{k}-\delta\left[E_{k}(x)-U_{k}\right]
$$

Equation (10) has a standard interpretation. When a worker of type $k$ is employed today, she works at a distance $x$ and she obtains an instantaneous utility equal to $\Omega_{k}+w_{k}\left(1-\tau x / \mu_{k}\right)-$ $f_{k}$. Then, this worker can lose his job with probability $\delta$ and experience a reduction in wealth equal to $E_{k}(x)-U_{k}$.

Next, we present the Bellman equations for the firm. Let $y$ be the productivity of a worker and let $\gamma$ denote the firm's search cost per unit of time. Since we assume constant returns to scale production, profits do not depend on firm size so we can think of all vacancies to be single worker firms. The expected discounted lifetime utility of a firm with a filled job and a firm with a vacancy, respectively denoted by $J_{k}$ and $V$, are given by:

$$
\begin{gathered}
r J_{k}\left(w_{k}\right)=y-w_{k}-\delta\left(J_{k}-V\right) \\
r V=-\gamma+\frac{2 m(\theta)}{\theta\left(u_{B}+u_{W}\right)}\left[u_{B} \int_{0}^{\widehat{x}_{B}}\left(J_{B}-V\right) d x+u_{W} \int_{0}^{\widehat{x}_{W}}\left(J_{W}-V\right) d x\right] .
\end{gathered}
$$

According to (11), a workers' productivity $y$ does not depend on her distance to the jobs, $x$. As a result, all employed workers are in terms of their productivity, identical from the firms' viewpoint. However, as we will show below, white workers can bargain a higher wage because they have a better outside option due to the fact that $\widehat{x}_{W}>\widehat{x}_{B}$. This implies that firms prefer black workers over white workers, but still hire white workers because it is more profitable to hire them than to wait for a black worker to arrive.

\footnotetext{
${ }^{17}$ For the model to make sense, we assume throughout that $\tau<2 \mu_{B}$ since this guarantees that $1>\tau x / \mu_{k}$, $\forall x \in[0,1 / 2]$ and $k \in\{B, W\}$.
} 


\section{The steady-state equilibrium}

A (steady-state) labor market equilibrium consists of labor market tightness, wages, unemployment levels and a maximum traveling distance, $\widehat{x}_{W}^{*}$ for black and white workers $\left(w_{B}^{*}, w_{W}^{*}, \widehat{x}_{B}^{*}, \widehat{x}_{W}^{*}, u_{B}^{*}, u_{W}^{*}, \theta^{*}\right)$ such that, given the matching technology, all agents (workers and firms) maximize their respective objective function. Labor market tightness is determined by a free-entry condition, wages by Nash bargaining, and maximum traveling distance by an indifference condition between the value of unemployment and the value of employment at the maximum acceptable distance. Finally, unemployment and vacancy levels follow from equilibrium labor market tightness and a steady-state condition on unemployment.

\subsection{Labor demand}

Firms enter in the labor market up to the point where they make zero (expected) profits, i.e. $V=0$. Using (11) and (12), we can write:

$$
\begin{gathered}
J_{k}=\frac{y-w_{k}}{r+\delta}, \\
\frac{u_{B} \widehat{x}_{B} J_{B}+u_{W} \widehat{x}_{W} J_{W}}{u_{B}+u_{W}}=\frac{\gamma \theta}{2 m(\theta)} .
\end{gathered}
$$

Combining (14) and (13) yields

$$
\frac{u_{B} \widehat{x}_{B}\left(y-w_{B}\right)+u_{W} \widehat{x}_{W}\left(y-w_{W}\right)}{u_{B}+u_{W}}=\frac{\gamma \theta(r+\delta)}{2 m(\theta)} .
$$

For given wages $w_{B}$ and $w_{W}$, we can derive the direct relationship between $\widehat{x}_{k}$ and $\theta$. By differentiating (15), we obtain:

$$
\frac{\partial \theta}{\partial \widehat{x}_{W}}>0 \quad \frac{\partial \theta}{\partial \widehat{x}_{B}}>0
$$

This result is quite intuitive. When the area of search increases so that workers are ready to accept jobs located further away, firms create more jobs (or equivalently more firms enter in the labor market) because they have more chance to fill up a vacancy since workers are less "picky".

\subsection{Wage determination}

The total intertemporal surplus is shared through a generalized Nash-bargaining process between the firm and the worker. As mentioned before, we assume that firms either do not 
observe the location of workers or more precisely, their $x$ (the distance between the workers and the firm's location) or that their location is not verifiable because if a worker living in location $i$ would earn more than the same worker living in location $i^{\prime}$, workers in location $i^{\prime}$ would have incentives to report a fake address in location $i$.

As a result, a worker and a firm only bargain over observable factors. ${ }^{18,19}$ However, even if firms do not know the exact location of each worker, they know that blacks use public transportation while whites use cars to commute (this will be shown below). In other words, firms do not observe $x$ but they observe $\widehat{x}_{B}$ and $\widehat{x}_{W}$. Since traveling time is non-verifiable, it is not part of the wage negotiation. As a result, in the wage bargaining, the value of employment is not given by (10) but by:

$$
r E_{k}^{d}=\Omega_{k}+w_{k}-f_{k}-\delta\left[E_{k}^{d}-U_{k}^{d}\right]
$$

where $U_{k}^{d}$, the disagreement payoff for the unemployed worker during bargaining is still given by $(9)$ while $E_{k}\left(x, w_{k}\right)$ is replaced by $E_{k}^{d}(x)$. Hence, during the bargaining process, the actual $x$ does not matter since only the average $x$ per type $k$ is taken into account. This is a standard statistical discrimination argument. The match surplus of workers that is relevant for the wage bargaining is thus $E_{k}^{d}-U_{k}^{d}$ while the surplus for the firms is: $J_{k}-V$, which reduces to $J_{k}$ because of the free entry condition. Nash wage bargaining then implies that:

$$
(1-\beta)\left[E_{k}^{d}-U_{k}^{d}\right]=\beta J_{k}
$$

where $0 \leq \beta \leq 1$ denotes the bargaining power of workers. In part A of the Appendix, we show that (17) implies:

$$
w_{k}=\frac{(1-\beta)(r+\delta) b+\beta\left[r+\delta+2 m(\theta) \widehat{x}_{k}\right] y}{r+\delta+2 \beta m(\theta) \widehat{x}_{k}} .
$$

For a given $\theta$, wages are increasing in the unemployment benefit $b$, the workers' productivity $y$, and the workers' bargaining power $\beta$. More interestingly, for a given $\theta$, by differentiating (18), we have:

$$
\frac{\partial w_{k}}{\partial \widehat{x}_{k}}=\frac{2(r+\delta) \beta m(\theta)(1-\beta)(y-b)}{\left[r+\delta+2 \beta m(\theta) \widehat{x}_{k}\right]^{2}}>0 .
$$

When the area of search $\widehat{x}_{k}$ increases for type- $k$ workers, they have a better outside option and therefore can bargain higher wages. Since labor-market tightness (i.e. job creation) for

\footnotetext{
${ }^{18}$ See also Gautier (2002) for a similar approach.

${ }^{19}$ One could also assume that when a firm and a worker bargain over a wage, it is the average commuting distance of each type of workers that is taken into account. This will not change the main results of this paper but will make the wage a direct function of commuting costs.
} 
blacks and whites is the same and equal to $\theta, \widehat{x}_{W}>\widehat{x}_{B}$, implies that white workers earn higher wages than black workers. In other words, by increasing the area of search, car access increases wages. This is a well-documented fact (see e.g. Gurley and Bruce, 2005).

\subsection{Maximum distance to jobs}

We must finally determine the maximum commuting distance a worker is willing to accept, $\widehat{x}_{k}$. In order to determine $\widehat{x}_{k}$, we use the asset values of unemployment and employment given by (9) and (10). Formally, $\widehat{x}_{k}$ is implicitly defined by the home-work distance that makes the worker indifferent between being employed or remaining unemployed:

$$
E_{k}\left(\widehat{x}_{k}, w_{k}\right)-U_{k}=0
$$

In part B of the Appendix, we show that (20) is equivalent to:

$$
\frac{m(\theta) w_{k} \tau}{\mu_{k}} \widehat{x}_{k}^{2}+\frac{\tau w_{k}(r+\delta)}{\mu_{k}} \widehat{x}_{k}-\left(w_{k}-b\right)(r+\delta)=0 .
$$

It is easy to verify that there is a unique positive solution to this equation that we denote by $\widehat{x}_{k}^{*}$. We show in part $\mathrm{B}$ of the Appendix that a condition for both $\widehat{x}_{W}^{*}<1 / 2$ and $\widehat{x}_{B}^{*}<1 / 2$ and the net wage to be strictly positive is (33). Note that if $\widehat{x}_{k}^{*} \geq 1 / 2$, for $k=B, W$, then there will be a trivial equilibrium where all workers, whatever their type $k$, accept all job offers. We also show in part B of the Appendix that, for a given $\theta$,

$$
\frac{\partial \widehat{x}_{k}^{*}}{\partial \mu_{k}}>0
$$

Indeed, when people use a faster transport mode, they also accept jobs involving longer commutes. If whites mainly use cars while blacks use public transportation, then this implies that $\widehat{x}_{W}^{*}>\widehat{x}_{B}^{*} \cdot{ }^{20}$

\subsection{Transport mode decision}

We now derive sufficient conditions for whites to choose cars and blacks to choose public transport. All whites use cars if they can afford it and if no individual white worker reaches

\footnotetext{
${ }^{20}$ The positive root of $\widehat{x}_{k}$ is increasing and convex in $w_{k}$ while, if we consider the relationship between $\widehat{x}_{k}$ and $w_{k}$ in (18), we obtain an increasing and concave function in $w_{k}$. This means that we cannot rule out that there may exist multiple (at most 2) equilibria. However, in our numerical simulations, for all reasonable parameter values that we tried, we only found one positive $\left(\widehat{x}_{k}, w_{k}\right)$ equilibrium pair. Moreover, even if there exist two equilibria, in both of them, the fast transport mode users have a higher wage and search over a larger area so that our main results (Proposition 1) remain unchanged.
} 
a higher utility by using public transport even if firms believe she travels by car. Blacks will always use public transport if they cannot afford a car but can afford to use public transportation.

The highest income that a black worker can obtain is when she is employed forever and perfectly matched to a firm (i.e. $x=0$ ). So, no black worker can afford a car if:

$$
\Omega_{B}+w_{B}<f_{W}
$$

The worst labor market state for a black worker is unemployment (in that case $x$ does not matter). As a result, blacks can always afford public transport if:

$$
\Omega_{B}+b>f_{B}
$$

Since we assumed that all workers can use exactly one transport mode, we can rule out that a worker chooses not to invest in transportation and simply collect $b$.

For whites, we need a condition that guarantees that all of them own a car. If the poorest white (who is unemployed) can afford a car, then they all can. So a sufficient condition for all whites to own cars is:

$$
\Omega_{W}+b>f_{W}
$$

Combining these three conditions gives:

$$
f_{B}-b<\Omega_{B}<f_{W}-w_{B}<f_{W}-b<\Omega_{W}
$$

Finally, we need to show that it is not profitable for an individual white worker to switch to public transport even if employers believe she has a car. Because employers observe neither car ownership nor residential location directly, they statistically discriminate and base expectations on aggregate car ownership rates for blacks and whites. When they bargain with a white worker, they believe that her area of search is $\widehat{x}_{W}$ if sufficiently many whites own a car and thus offer her a wage $w_{W}$. Let $\widehat{x}_{W}^{\text {public }}$ be the maximum acceptable distance for a deviant white worker who takes public transport. Its value is given by (35) in part $\mathrm{C}$ of the Appendix and we show that $\widehat{x}_{W}^{\text {public }}<\widehat{x}_{W}\left(\widehat{x}_{W}\right.$ is given by $\left.(21)\right)$. In part $\mathrm{C}$ of the Appendix, we also show that a necessary and sufficient condition for whites to never deviate and thus to always have cars is:

$$
\left(\widehat{x}_{W}-\widehat{x}_{W}^{\text {public }}\right) \Omega_{W}+\widehat{x}_{W}\left(A I_{W}^{c a r}-f_{W}\right)-\widehat{x}_{W}^{p u b l i c}\left(A I_{W}^{p u b l i c}-f_{B}\right)>\frac{r\left(f_{W}-f_{B}\right)}{2 m(\theta)}
$$

where $A I_{W}^{c a r}$ and $A I_{W}^{\text {public }}$ are the average income of a white worker having a car and using public transportation, respectively, and are given by (47) and (48). 
To sum up, blacks will not use cars if $\Omega_{B}$ and $y$ are sufficiently low, implying that our model is only relevant for the lower labor market segments (i.e. low-skill workers). Whites own cars if $\Omega_{W}$ is sufficiently large. Of course, there are weaker conditions where some blacks own cars and/or some whites use public transport but as long as a larger fraction of whites own cars, our results will qualitatively be the same. Finally, if a small fraction of blacks has equal wealth as white workers, they may still opt for public transportation if firms offer them lower wages because they believe that blacks will not travel by car.

As stated in the introduction, the initial wealth $\Omega_{k}$ can also capture the access to the capital market. Assumption (27) implies that if blacks have a more difficult access to the capital market than whites, then they are more likely to use public transportation. Using data from the 1992, 1995, 1998, and 2001 waves of the Survey of Consumer Finances (SCF), Charles et al. (2008) show that, not only blacks pay higher interest rates than whites on the loans used to purchase vehicles, but that they are much more likely to have recently been turned down for a vehicle loan.

\subsection{The steady-state equilibrium}

Definition 1 A steady-state equilibrium is a tuple $\left(w_{B}^{*}, w_{W}^{*}, \widehat{x}_{B}^{*}, \widehat{x}_{W}^{*}, u_{B}^{*}, u_{W}^{*}, \theta\right)$ such that equations (18), (21), (5), (6) and (15) are satisfied.

Our main result can be stated as follows (the proof can be found in part D of the Appendix):

Proposition 1 Assume that (26) and (27) hold. Then, white workers use cars while black workers take public transportation to commute to their workplace. Consequently, whites will search over a wider area than blacks, i.e. $\widehat{x}_{B}^{*}<\widehat{x}_{W}^{*}<1 / 2,{ }^{21}$ earn a higher wage, i.e. $w_{W}^{*}>w_{B}^{*}$, and experience a lower unemployment rate, i.e. $u_{W}^{*}<u_{B}^{*}$.

If there is a wealth difference between blacks and whites, i.e. $\Omega_{W}$ is sufficiently large compared to $\Omega_{B}$, then whites will be able to afford to buy a car while blacks will be forced to use public transportation. Because of the bad public transportation system in the United States, black workers have difficulties to reach jobs located too far away from their residential location and therefore they will only accept job offers located relatively close to where they live. White workers do accept jobs located further away because of their faster and

\footnotetext{
${ }^{21} \mathrm{~A}$ condition that guarantees that both $\widehat{x}_{W}^{*}<1 / 2, \widehat{x}_{B}^{*}<1 / 2$ and the net wage $w_{k}\left(1-\tau x / \mu_{k}\right)$ to be always strictly positive whatever $x \in[0,1 / 2], k \in\{B, W\}$ is (33), which is given in part B of the Appendix.
} 
"smoother" transport mode. As a result, whites spend less time unemployed since more job offers will be acceptable for them and obtain a higher wage because their bargaining position in better. ${ }^{22}$

Note that the average distance to jobs (not to acceptable jobs) is the same for blacks and whites and equal to $1 / 4$. In the real-world, this is not true; in most US cities, jobs are located relatively far away from where blacks live (see the spatial mismatch literature exposed in the Introduction and the literature survey by Ihlanfeldt and Sjoquist, 1998). So if we had started with ex ante inequalities in the distance to jobs between blacks and whites, the differences in outcomes would have been even larger.

To sum-up, our model endogenously shows that, compared to whites, blacks $(i)$ do not own a car, $(i i)$ experience higher unemployment rates $\left(u_{B}^{*}>u_{W}^{*}\right)$ and longer unemployment spells $\left(1 /\left[2 m(\theta) \widehat{x}_{B}^{*}\right]>1 /\left[2 m(\theta) \widehat{x}_{W}^{*}\right]\right),(i i i)$ earn lower wages $\left(w_{B}^{*}<w_{W}^{*}\right),(i v)$ can spend on average more time commuting to work $\left(\widehat{x}_{B}^{*} /\left(2 \mu_{B}\right)>\widehat{x}_{W}^{*} /\left(2 \mu_{W}\right)\right),(v)$ travel on average less miles to go to their jobs $\left(\widehat{x}_{B} / 2<\widehat{x}_{W} / 2\right)$, and $(v i)$ search for jobs over a smaller area $\left(\widehat{x}_{B}^{*}<\widehat{x}_{W}^{*}\right)$.

Results $(i v)$ and $(v)$ are surprising and not straightforward but are well-documented features of the spatial labor market of black and white workers. Indeed, even though blacks are on average further away from jobs, they live closer (in miles) to jobs when they are employed but spend more time traveling. The time cost per mile traveled is thus substantially higher for blacks than for whites. There is indeed a difference between commuting distance and commuting time. In the United States in the central city (where a large fraction of blacks live), even over shorter distances, travel times are quite long, especially for people who rely on public transportation. For example, in 1995, the average commute distance for workers using private transportation was twelve miles, compared to thirteen miles for those reliant on public transportation. Commute times, however, were more than twice as long on public transit than for those who used private vehicles - twenty two minutes compared to forty-two minutes (Hu and Young, 1999). Results (iv) and (v) are due to the lack of car access among the black population while the fact that blacks are on average further away from jobs is often attributed to housing discrimination (Ross and Yinger, 2002; Dymski, 2006) and the willingness to live together (Ihlanfeldt and Scafidi, 2002). In our model, result (iv) is not always true since $\widehat{x}_{B}^{*}<\widehat{x}_{W}^{*}$ and $\mu_{B}<\mu_{W}$. However, if using cars is a much faster transport mode than public transportation, then this will hold because the first direct effect is stronger than the second indirect effect.

\footnotetext{
${ }^{22}$ We have run different numerical simulations (that are available upon request) of this model satisfying conditions (26) and (27). We obtain all the results of Proposition 1.
} 
Most empirical studies have indeed shown that the mean daily commute is lower for whites than for blacks (see e.g. Patacchini and Zenou, 2005, for the UK, Chung et al. 2001, and Gottlieb and Lentnek, 2001, for the US.) while white commuters have longer average commute distances than blacks (Holzer et al., 1994; Taylor and Ong, 1995). In particular, using the National Longitudinal Survey Youth Cohort (NLSY) for 1981 and 1982, Table 1 from Holzer et al. (1994) displays interesting statistics, which confirm results $(i)-(v)$ and thus Proposition 1.

Table 1. Search and labor market outcomes for blacks and whites in the US ${ }^{23}$

\begin{tabular}{|l|c|c|}
\hline & White males & Black males \\
\hline Miles traveled to work & $\begin{array}{c}8.017 \\
(11.352)\end{array}$ & $\begin{array}{c}6.977 \\
(9.879)\end{array}$ \\
\hline Miles traveled searching $\widehat{x}_{k}^{*}$ & $\begin{array}{c}19.923 \\
(25.328)\end{array}$ & $\begin{array}{c}18.558 \\
(22.718)\end{array}$ \\
\hline Time spent traveling to work $\widehat{x}_{k}^{*} / 2 \mu$ & 15.841 & 18.603 \\
& $(15.058)$ & $(17.482)$ \\
\hline Time spent per mile traveled & 3.351 & 4.899 \\
& $(3.851)$ & $(5.963)$ \\
\hline Log (wage), $1981 w_{k}^{*}$ & 6.080 & 5.997 \\
& $(0.393)$ & $(0.370)$ \\
\hline Log (wage), $1982 w_{k}^{*}$ & 6.246 & 6.112 \\
& $(0.447)$ & $(0.421)$ \\
\hline Employment, $19811-u_{k}^{*}$ & 0.594 & 0.456 \\
\hline Employment, $19821-u_{k}^{*}$ & 0.618 & 0.452 \\
\hline Log (duration of unemployment) $1 /\left[2 m(\theta) \widehat{x}_{k}^{*}\right]$ & 1.591 & 1.838 \\
& $(0.841)$ & $(0.913)$ \\
\hline
\end{tabular}

First, Table 1 shows lower employment rates and wages for blacks, as well as durations of unemployment that are over 25-30 percent higher for blacks than for whites. Second, blacks spend significantly more time travelling to work than whites, even though the distance traveled is lower for blacks. This is certainly due to different transport modes (in their study, 68.5 percent of white males own a car while this number is 43.8 percent for blacks; also 4.1 percent of white males use mass transit while this number is 18.9 percent for blacks). The time spent per mile traveled is thus considerably higher for blacks - about 46 percent higher.

\footnotetext{
${ }^{23}$ Values given in this table are means while those given in parentheses are standard deviations.
} 
Finally, black job seekers have a smaller area of search than whites. Again, following our model, this is due to different transport modes between blacks and whites.

\section{Discussion and policy implications}

We have argued that because of wealth differences, whites use cars to commute whereas blacks use public transportation. The set of feasible jobs in terms of distance is therefore larger for whites. This improves their bargaining position and results in higher wages and lower unemployment rates for whites. Allowing workers to vary their search intensity would only make the differences larger because the returns to search are higher for whites.

All our results are obtained by assuming that firms have no taste for discrimination and that ex ante blacks and whites are located at the same average distance to jobs. It is well-documented that both discrimination (Altonji and Blank, 1999) and distance to jobs (Ihlanfeldt and Sjoquist, 1998) are important factors that negatively affect the labor market outcomes of black workers. Adding these elements in our model would lead to more pronounced outcomes between blacks and whites.

As in the standard search-matching models (Diamond, 1982, Mortensen and Pissarides, 1999), there are two types of search externalities: negative intra-group externalities (more job seekers reduce the job-acquisition rate) and positive inter-group externalities (more searching firms increase the job-acquisition rate). In addition, there are interracial search externalities due to the fact that there is some asymmetry in the search process between blacks and whites. Indeed, white workers exert negative externalities on black workers because they obtain a job at a faster rate than blacks (i.e. $\left.\widehat{x}_{W}^{*}>\widehat{x}_{B}^{*}\right)$ and are better paid $\left(w_{W}^{*}>w_{B}^{*}\right)$ which reduces vacancy supply. ${ }^{24}$

Investments in public transport can have a substantial impact on search activities of lowincome workers and thus on their unemployment rate. Indeed, if labor participation for black workers is affected by poor access to job locations and poor worker mobility, and if public transportation services are designed to effectively link workers with areas of concentrated employment, then increased access to public transit should yield higher levels of employment in particular for blacks (Sanchez, 1998, 1999; Blumemberg and Manville, 2004). ${ }^{25}$

\footnotetext{
${ }^{24}$ There is a second order positive effect, namely that a higher $\widehat{x}_{W}^{*}$ has a positive effect on labor market tightness, $\theta$ and the blacks also benefit from this.

${ }^{25}$ Researchers studying the relationship between transportation and employment find that reliable transportation leads to increased access to job opportunity, higher earning, and increased employment stability (Blumemberg, 2000; Cervero et al., 2002; Ong, 2002; Holzer and Ihlanfeldt, 1996).
} 
Alternatively, programs that help job takers (especially blacks) obtain a used car - a secured loan for purchase, a leasing scheme, a revolving credit arrangement - may offer real promise and help low-skill workers obtaining a job. This is a standard policy that has been advocated in the US (see e.g. Pugh, 1998). Stoll (1999) shows that increasing blacks' and Latinos' access to cars will lead to greater geographic job search. As in our model, this in turn will lead to higher employment and wages for these groups. Using data from the UK, Patacchini and Zenou (2005) find similar results. They find that, for a given time distance to jobs (measured by the average commuting time of the employed in a given area), unemployed white workers search more intensively than unemployed black workers. They also show that giving to black workers the mean level of white (time) distance to jobs and white car access would close the racial gap in search intensity by 50.31 percent. Raphael and Stoll (2001) also found that raising minority car-ownership rates to the white car ownership rate would considerably narrow inter-racial employment rate differentials (see also Raphael and Rice, 2002, and Gurley and Bruce, 2005, who found positive effects of car access on employment). ${ }^{26}$ Also, if one believes that the low rate of car ownership among black families is driven by discrimination in the automobile insurance and credit markets, then the government should enforce anti-discrimination laws that prevent such behavior.

Some researchers believe that public funds should be spent helping welfare recipients secure cars (Blumenberg and Waller, 2003; O'Regan and Quigley, 1998; Ong, 2002; Waller and Hughes, 1999; Shen, 2001). In the United States, the welfare program allows states to use federal block grants to provide direct purchase assistance for automobiles, to help pay for insurance, and to provide loans for would-be buyers. Ways to Work, a partnership that secures two-year loans for Temporary Assistance for Needy Families (TANF) recipients in twenty-three cities across seventeen states, reported in 2001 that over 85 percent of its loans had gone to vehicle purchase (Goldberg, 2001). Early evaluations of the program show that participants average as much as a 20-percent increase in monthly income once the loan is received. ${ }^{27}$ One disadvantage of stimulating car use is that average speed is likely to be

\footnotetext{
${ }^{26}$ Since car ownership and employment are likely to be simultaneously determined, most of these papers either find instruments or use a natural experiment to obtain a casual relationship. For example, Holzer et al. (2003) use an expansion of the San Francisco Bay Area's heavy rail system to have an exogenous change in the accessibility of inner-city minority communities to a concentrated suburban employment center. On the other hand, Raphael and Stoll (2001) use an instrument variable strategy to overcome the simultaneity problem between car ownership and employment. Gurley and Bruce (2005) convincingly instrument for car ownership and also finds a positive relationship.

${ }^{27}$ Tennessee has also recognized the importance of car access for welfare recipients. In addition to a standard vehicle asset exemption amount, their unique benefit program, First Wheels, provides zero-interest loans for the purchase of a used automobile for program participants and for leavers up to twelve months
} 
decreasing in the total number of cars.

Our model sheds some light on the policies discussed above. In particular, by providing the exact mechanism by which car ownership affects the labor-market outcomes of black workers, it helps designing the appropriate policy aiming at improving the outcomes of minority workers.

\section{References}

[1] Altonji, J.G. and R.M. Blank (1999), "Race and gender in the labor market," In: D. Card and O. Ashenfelter (Eds.), Handbook of Labor Economics, Vol. 3, Amsterdam: Elsevier Science, pp. 3143-3259.

[2] Arrow, K.J. (1973), "The theory of discrimination," In: O. Ashenfelter and A. Rees (Eds.), Discrimination in Labor Markets, Princeton: Princeton University Press, pp. $3-33$.

[3] Barsky, R.B., Bound, J., Charles, K.K. and J.P. Lupton (2002), "Accounting for the black-white wealth gap: A nonparametric approach," Journal of the American Statistical Association 97, 663-673.

[4] Blumemberg, E. (2000), "On the way to work: Welfare recipients and barriers to employment," Economic Development Quarterly 16, 314-325.

[5] Blumemberg, E. and M. Manville (2004), "Beyond the spatial mismatch hypothesis: Welfare recipients and transportation policy," Journal of Planning Literature 19, 182205.

[6] Blumenberg, E. and M. Waller (2003), "The long journey to work: A federal transportation policy for urban families," Brookings Institution, Washington DC.

[7] Brueckner, J.K. (2000), "Urban sprawl: Diagnosis and remedies," International Regional Science Review 23, 160-171.

[8] Brueckner, J.K. (2001), "Urban sprawl: Lessons from urban economics," BrookingsWharton Papers on Urban Affairs 2, 65-97.

after cash assistance payment end. Gurley and Bruce (2005) show that this program has increased the probability of being employed and leaving welfare. 
[9] Brueckner, J.K., Thisse, J-F. and Y. Zenou (2002), "Local labor markets, job matching and urban location," International Economic Review 43, 155-171.

[10] Brueckner, J.K. and Y. Zenou (2003), "Space and unemployment: The labor-market effects of spatial mismatch," Journal of Labor Economics 21, 242-266.

[11] Cervero, R., Sandoval, O. and J. Landis (2002), "Transportation as a stimulus of welfareto-work. Private versus public mobility," Journal of Planning Education and Research $22,50-63$.

[12] Cohen, M. (2007), "Imperfect competition in auto lending: Subjective markup, racial disparity, and class action litigation," Vanderbilt Law School and Economics Research Paper No. 07-01.

[13] Charles, K.K., Hurst, E. and M. Stephens Jr. (2008), "Rates for vehicle loans: Race and loan source," American Economic Review, Papers and Proceedings 98, 315-320.

[14] Charles, K.K. and E. Hurst (2002), "The transition to home ownership and the blackwhite gap," Review of Economics and Statistics 84, 281-297.

[15] Chung, C., Myers, S.L., Jr. and L. Saunders (2001), "Racial differences in transportation access to employment in Chicago and Los Angeles, 1980 and 1990," American Economic Review, Papers and Proceedings 91, 174-177.

[16] Coulson, E. Laing, D. and P. Wang (2001), "Spatial mismatch in search equilibrium," Journal of Labor Economics 19, 949-972.

[17] Diamond P.A. (1982), Aggregate demand management in search equilibrium, Journal of Political Economy 90, 881-894.

[18] Dymski, G.A. (2006), "Discrimination in the credit and housing markets: Findings and challenges," In: W.M. Rodgers III (Ed.), Handbook on the Economics of Discrimination, New York: Edward Elgar Publishing.

[19] Fernandez, R.M. (1994), "Race, space, and job accessibility: Evidence from a plant relocation," Economic Geography 70, 390-416.

[20] Fernandez, R.M. and C. Su (2004), "Space in the study of labor markets," Annual Review of Sociology 30, 545-569. 
[21] Gautier, P.A. (2002), "Unemployment and search externalities in a model with heterogeneous jobs and workers," Economica 69, 21-40.

[22] Gautier, P.A, Teulings, C.N. and A.P. van Vuuren (2006), "Labor market search with two sided heterogeneity: Hierarchical versus circular models," In: H. Bunzel, B.J. Christensen, G.R. Neumann, and J.M. Robin (Eds.), Structural Models of Wage and Employment Dynamics, conference volume in honor of Dale Mortensen, Amsterdam: Elsevier Science, pp. 117-132.

[23] Gautier, P.A., Teulings, C.N. and A.P. van Vuuren (2008), "On the job search and sorting," Unpublished manuscript, Tinbergen Institute.

[24] Glaeser, E.L. and M.E. Kahn (2001), "Decentralized employment and the transformation of the American city," Brookings-Wharton Papers on Urban Affairs 2, 1-64.

[25] Glaeser, E.L. and M.E. Kahn (2004), "Sprawl and urban growth," In: J.V. Henderson and J.-F. Thisse (Eds.), Handbook of Regional and Urban Economics Vol. 4, Amsterdam: Elsevier Science, pp. 2498-2527.

[26] Glaeser, E.L., Kahn, M.E. and J. Rappaport (2008), "Why do the poor live in cities?," Journal of Urban Economics 63, 1-24.

[27] Glaeser, E.L. and J.M. Shapiro (2003), "Urban growth in the 1990s: Is city living back?" Journal of Regional Science 43, 139-165.

[28] Gobillon, L., Selod, H. and Y. Zenou (2007), "The mechanisms of spatial mismatch," Urban Studies 44, 2401-2427.

[29] Goldberg, H. (2001), "State and country supported car ownership programs can help low-income families secure and keep jobs, Center on Budget and Policy Priorities, Washington, DC.

[30] Gottlieb, P.D. and B. Lentnek (2001), "Spatial mismatch is not always a central-city problem: An analysis of commuting behavior in Cleveland, Ohio, and its suburbs", Urban Studies 38, 1161-1186.

[31] Gurley, T. and D. Bruce (2005), "The effects of car access on employment outcomes for welfare recipients," Journal of Urban Economics 58, 250-272.

[32] Hamilton, J., Thisse, J.-F. and Y. Zenou (2000), "Wage competition with heterogeneous workers and firms," Journal of Labor Economics 18, 453-472. 
[33] Hess, D.B. (2005), "Access to employment for adults in poverty in the Buffalo-Niagara region", Urban Studies 42, 1177-1200.

[34] Holzer, H.J. and K.R. Ihlanfeldt (1996), "Spatial factors and the employment of blacks at the firm level," New England Economic Review, 65-86.

[35] Holzer H.J., Ihlanfeldt, K.R and D.L. Sjoquist (1994), "Work, search, and travel among white and black youth," Journal of Urban Economics 35, 320-345.

[36] Holzer H.J., Quigley, J.M. and S. Raphael (2003), "Public transit and the spatial distribution of minority employment: Evidence from a natural experiment," Journal of Policy Analysis and Management 22, 415-444.

[37] Hu, P.S. and J.R. Young (1999), Summary of Travel Trends: 1995 Nationwide Personal Transportation Survey, Washington, DC: Federal Highway Administration, US Department of Transport.

[38] Ihlanfeldt, K.R. (2006), "A primer on spatial mismatch within urban labor markets," In: R. Arnott and D. McMillen (Eds.), A Companion to Urban Economics, Boston: Blackwell Publishing, pp. 404-417.

[39] Ihlanfeldt, K.R. and Scafidi, B. (2002), "Black self-segregation as a cause of housing segregation. Evidence from the multi-city study of urban inequality," Journal of Urban Economics 51, 366-390.

[40] Ihlanfeldt, K.R. and D.L. Sjoquist (1998), "The spatial mismatch hypothesis: a review of recent studies and their implications for welfare reform," Housing Policy Debate 9, 849-892.

[41] Kain, J.F. (1968), "Housing segregation, negro employment, and Metropolitan decentralization," Quarterly Journal of Economics 82, 175-197.

[42] Kawabata, M. and Q. Shen (2007), "Commuting inequality between cars and public transit: The case of San Francisco Bay area, 1990-2000," Urban Studies 44, 1759-1780.

[43] King, M.L., Jr. (1986), "A testament of hope," In: J.M. Washington (Ed.), A Testament of Hope: The Essential Writtings and Speeches of Martin Luther King, Jr., San Francisco: Harper Collins, pp. 313-328.

[44] LeRoy, S.F. and J. Sonstelie (1983), "Paradise lost and regained: Transportation innovation, income, and residential location," Journal of Urban Economics 13, 67-89. 
[45] Madden, J. F. (1985), "Urban wage gradients: Empirical evidence," Journal of Urban Economics 18, 291-301.

[46] Marimon R. and F. Zilibotti (1999), "Unemployment versus mismatch of talents: Reconsidering unemployment benefits," Economic Journal 109, 266-291.

[47] Manning, A. (2003), "The real thin theory: Monopsony in modern labour markets", Labour Economics 10, 105-131.

[48] Mayer, C., Pence, K. and Shane M. Sherlund (2008), "The rise in mortgage defaults," Finance and Economics Discussion Series No. 2008-59, Federal Reserve Board, Whashington, DC.

[49] Mortensen, D.T. (1982), "The matching process as a noncooperative bargaining game," In: J.J. McCall (Ed.), The Economics of Information and Uncertainty, Chicago: University of Chicago Press.

[50] Mortensen, D.T. and C.A. Pissarides (1999), "New developments in models of search in the labor market," In: D. Card and O. Ashenfelter (Eds.), Handbook of Labor Economics, Vol. 3, Amsterdam: Elsevier Science, pp. 2567-2627.

[51] Nechyba, T.J. and R.P. Walsh (2004), "Urban sprawl," Journal of Economic Perspectives 18, 177-200.

[52] Ong, P. (2002), "Car ownership and welfare-to-work," Journal of Policy Analysis and Management 21, 239-252.

[53] O’Regan, K.M. and J.M. Quigley (1998), "Cars for the poor," Access12, 20-25.

[54] Owen, D. and A.E. Green (2000), "Estimating commuting flows for minority groups in England and Wales," Journal of Ethnic and Migration Studies 26, 581-608.

[55] Patacchini, E. and Y. Zenou (2005), "Spatial mismatch, transport mode, and search decisions in England," Journal of Urban Economics 58, 62-90.

[56] Phelps, E. (1972), "The statistical theory of racism and sexism," American Economic Review 62, 659-661.

[57] Pissarides, C.A. (2000), Equilibrium Unemployment Theory, Second edition, Cambridge: The MIT. Press. 
[58] Pugh, M. (1998), "Barriers to work: The spatial divide between jobs and welfare recipients in Metropolitan Areas," Discussion Paper 8/98, The Brookings Institution, Center on Urban and Metropolitan Policy.

[59] Raphael, S. and L. Rice (2002), "Car ownership, employment, and earnings," Journal of Urban Economics 52, 109-130.

[60] Raphael, S. and M.A. Stoll (2001), "Can boosting minority car-ownership rates narrow inter-racial employment gaps?" Brookings-Wharton Papers on Urban Economic Affairs 2, 99-145.

[61] Ross, S. and J. Yinger (2002), Color of Credit: Mortgage Discrimination, Research Methods, and Fair Lending Enforcement, Cambridge, MA: MIT Press.

[62] Rupert, P., Stancanelli, E., and E. Wasmer (2009), "Commute distance matters in search models," Unpublished manuscript, University of California, Santa Barbara.

[63] Salop, S. (1979), "Monopolistic competition with outside goods," Bell Journal of Economics 10, 141-156.

[64] Sanchez, T.W. (1998), "Equity analysis of personal transportation system benefits," Journal of Urban Affairs 20, 69-86.

[65] Sanchez, T.W. (1999), "The connection between public transit and employment. The cases of Portland and Atlanta," Journal of the American Planning Association 65, 284296.

[66] Sasaki, K. (1990), "Income class, modal choice, and urban spatial structure," Journal of Urban Economics 27, 322-343.

[67] Sato, Y. (2001), "Labor heterogeneity in an urban labor market," Journal of Urban Economics 50, 313-337.

[68] Sato, Y. (2004), "City structure, search, and workers' job acceptance behavior," Journal of Urban Economics 55, 350-370.

[69] Schwartz, A. (1976), "Migration, age, and education," Journal of Political Economy 84, 701-719.

[70] Seater,J.J. ( 1979), "Job search and vacancy contracts," American Economic Review 69, 411-419. 
[71] Shen, Q. (1998), "Location characteristics of inner-city neighborhoods and employment accessibility of low-wage workers," Environment and Planning B 25, 345-365.

[72] Shen, Q. (2001), "A spatial analysis of job openings and access in a U.S. metropolitan area," Journal od the American Planning Association 67, 53-68.

[73] Small, K. A. (1992), Urban Transportation Economics, Chur: Harwood Academic Publishers.

[74] Smith, T.E. and Y. Zenou (2003), "Spatial mismatch, search effort and urban spatial structure," Journal of Urban Economics 54, 129-156.

[75] Stoll, M.A. (2005), "Geographical skills mismatch, job search and race," Urban Studies 42, 695-717.

[76] Taylor, B.D. and P.M. Ong (1995), "Spatial mismatch or automobile mismatch? An examination of race, residence and commuting in US metropolitan areas," Urban Studies $32,1453-1473$.

[77] Waller, M. and M.A. Hughes (1999), "Working far from home: Transportation and welfare reform in the ten bid states," Progressive Policy Institute and Public/Private Ventures, Washington, DC.

[78] Wassmer, R.W. (2008), "Causes of urban sprawl in the United States: Auto reliance as compared to natural evolution, flight from blight, and local revenue reliance," Journal of Policy Analysis and Management 27, 536-555.

[79] White, M. J. (1999), "Urban models with decentralized employment: Theory and empirical work", In: P. Cheshire and E.S. Mills (Eds.), Handbook of Regional and Urban economics. Volume 3: Applied Urban Economics, Amsterdam: North Holland, pp. 13751412.

[80] Zax, J.S. and J.F. Kain (1996), "Moving to the suburbs: Do relocating companies leave their black employees behind?," Journal of Labor Economics, 14, 472-493.

[81] Zenou, Y. (2009), Urban Labor Economics, Cambridge: Cambridge University Press. 


\section{Appendix}

\section{A Determination of the wage}

The value equation (9) can be written as:

$$
\begin{aligned}
r U_{k}^{d} & =\Omega_{k}+b-f_{k}+m(\theta)\left[2 \int_{0}^{\widehat{x}_{k}}\left[E_{k}^{d}-U_{k}^{d}\right] d x\right] \\
& =\Omega_{k}+b-f_{k}+2 m(\theta) \widehat{x}_{k}\left[E_{k}^{d}-U_{k}^{d}\right] .
\end{aligned}
$$

Now, by subtracting (28) from (16), we obtain:

$$
E_{k}^{d}-U_{k}^{d}=\frac{w_{k}-b}{r+\delta+2 m(\theta) \widehat{x}_{k}} .
$$

Plugging the value of $E_{k}^{d}-U_{k}^{d}$ from (29) and of $J_{k}$ from (13) into (17) yields

$$
(1-\beta)\left[\frac{w_{k}-b}{r+\delta+2 m(\theta) \widehat{x}_{k}}\right]=\beta\left(\frac{y-w_{k}}{r+\delta}\right) .
$$

By manipulating this expression, we obtain (18).

\section{B Determination of the maximum area of search}

First, since the value of employment for type $k$ depends linearly on $x$, only through traveling time $\frac{x}{\mu_{k}}$, we can write

$$
\frac{1}{\widehat{x}_{k}} \int_{0}^{\widehat{x}_{k}} E_{k}\left(x, w_{k}\right) d x=\mathbb{E}_{x}\left[E_{k}\left(x, w_{k}\right) \mid x<\widehat{x}_{k}\right]=E_{k}\left[\mathbb{E}_{x}\left(x \mid x<\widehat{x}_{k}\right), w_{k}\right]=E_{k}\left(\widehat{x}_{k} / 2\right),
$$

where the last step follows from, $\mathbb{E}_{x}\left(x \mid x<\widehat{x}_{k}\right)=\widehat{x}_{k} / 2$. Therefore,

$$
\int_{0}^{\widehat{x}_{k}} E_{k}\left(x, w_{k}\right) d x=\widehat{x}_{k} E_{k}\left(\widehat{x}_{k} / 2\right) .
$$

This implies that (9) can be written as:

$$
\left[r+2 m(\theta) \widehat{x}_{k}\right] U_{k}=\Omega_{k}+b-f_{k}+2 m(\theta) \widehat{x}_{k} E_{k}\left(\widehat{x}_{k} / 2\right) .
$$

If we evaluate (10) at $x=\widehat{x}_{k} / 2$, we get:

$$
(r+\delta) E_{k}\left(\widehat{x}_{k} / 2, w_{k}\right)=\Omega_{k}+w_{k}\left(1-\tau \frac{\widehat{x}_{k} / 2}{\mu_{k}}\right)-f_{k}+\delta U_{k} .
$$


Combining these two equations leads to:

$$
r U_{k}=\frac{\left(\Omega_{k}+b-f_{k}\right)(r+\delta)}{r+\delta+2 m(\theta) \widehat{x}_{k}}+\frac{2 m(\theta) \widehat{x}_{k}}{r+\delta+2 m(\theta) \widehat{x}_{k}}\left[\Omega_{k}+w_{k}\left(1-\tau \frac{\widehat{x}_{k} / 2}{\mu_{k}}\right)-f_{k}\right] .
$$

If we evaluate $(10)$ at $x=\widehat{x}_{k}$, we get:

$$
(r+\delta) E_{k}\left(\widehat{x}_{k}, w_{k}\right)=\Omega_{k}+w_{k}\left(1-\tau \frac{\widehat{x}_{k}}{\mu_{k}}\right)-f_{k}+\delta U_{k} .
$$

Using this last equation, (20) can be written as:

$$
\Omega_{k}+w_{k}\left(1-\tau \frac{\widehat{x}_{k}}{\mu_{k}}\right)-f_{k}=r U_{k}
$$

Using the value of $r U_{k}$ in (31), this last equation can be written as:

$$
\begin{aligned}
& \frac{\left(\Omega_{k}+b-f_{k}\right)(r+\delta)}{r+\delta+2 m(\theta) \widehat{x}_{k}}+\frac{2 m(\theta) \widehat{x}_{k}}{r+\delta+2 m(\theta) \widehat{x}_{k}}\left[\Omega_{k}+w_{k}\left(1-\tau \frac{\widehat{x}_{k} / 2}{\mu_{k}}\right)-f_{k}\right] \\
= & \Omega_{k}+w_{k}\left(1-\tau \frac{\widehat{x}_{k}}{\mu_{k}}\right)-f_{k},
\end{aligned}
$$

which is equivalent to:

$$
\frac{m(\theta) w_{k} \tau}{\mu_{k}} \widehat{x}_{k}^{2}+\frac{\tau w_{k}(r+\delta)}{\mu_{k}} \widehat{x}_{k}-\left(w_{k}-b\right)(r+\delta)=0 .
$$

There are two roots in this equation but only one is strictly positive. It is given by:

$$
\widehat{x}_{k}^{*}=-\frac{\tau(r+\delta)}{2 m(\theta) \tau}+\frac{\mu_{k}}{2 m(\theta) w_{k} \tau} \sqrt{\left(\frac{\tau w_{k}(r+\delta)}{\mu_{k}}\right)^{2}+4 \frac{m(\theta) w_{k} \tau\left(w_{k}-b\right)(r+\delta)}{\mu_{k}}} .
$$

Since $w_{k}$ is not directly affected by $\mu_{k}$ but only indirectly through $\widehat{x}_{k}$ (see (18)), we have:

$$
\frac{\partial \widehat{x}_{k}}{\partial \mu_{k}}=\frac{m(\theta) w_{k} \tau \widehat{x}_{k}^{2}+\tau w_{k}(r+\delta) \widehat{x}_{k}}{2 m(\theta) w_{k} \tau \widehat{x}_{k} \mu_{k}+\tau w_{k}(r+\delta) \mu_{k}}>0 .
$$

Denote

$$
\Phi\left(\widehat{x}_{W}\right)=\frac{m(\theta) w_{W} \tau}{\mu_{W}} \widehat{x}_{W}^{2}+\frac{\tau w_{W}(r+\delta)}{\mu_{k}} \widehat{x}_{W}-\left(w_{W}-b\right)(r+\delta) .
$$

Since $\widehat{x}_{W}>\widehat{x}_{B}$, for $\widehat{x}_{W}<1 / 2$ and $\widehat{x}_{B}<1 / 2$, we must check that

$$
\Phi(1 / 2)>0
$$

which is equivalent to:

$$
\frac{\tau}{2 \mu_{W}}\left(1+\frac{m(\theta)}{2(r+\delta)}\right)>1-\frac{b}{w_{W}}
$$


Combining this condition with the one that guarantees that the net wage $w_{k}\left(1-\tau x / \mu_{k}\right)$ is strictly positive, $\forall x \in[0,1 / 2], k \in\{B, W\}$, i.e. $\tau<2 \mu_{B}$, we obtain

$$
\left(1-\frac{b}{w_{W}}\right)\left[\frac{2(r+\delta)}{2(r+\delta)+m(\theta)}\right] \mu_{W}<\frac{\tau}{2}<\mu_{B}
$$

which is feasible since $\left(1-\frac{b}{w_{W}}\right)\left[\frac{2(r+\delta)}{2(r+\delta)+m(\theta)}\right]<1$.

\section{Condition for whites to prefer cars}

We need to verify that whites always prefer to use a car over public transportation because the net benefits of a car exceed its net cost. Therefore, we define the following steady-state value function of an unemployed white worker having a car:

$$
r U_{W}^{c a r}=\Omega_{W}+b-f_{W}+m(\theta)\left[2 \int_{0}^{\widehat{x}_{W}}\left[E_{W}^{c a r}\left(x, w_{W}\right)-U_{W}^{c a r}\right] d x\right]
$$

which is (9). Let $\widehat{x}_{W}^{\text {public }}$ be the maximum acceptable distance of a deviant white worker who travels by public transport. Observe that this white person still earns the same wage $w_{W}$ as other whites who use cars because firms do not observe transport mode directly and expect that all whites use cars. This is a standard statistical discrimination argument. The values of $\widehat{x}_{W}^{\text {public }}$ can be calculated in a similar way as in (21) and are implicitly defined by:

$$
\frac{m(\theta) w_{W} \tau}{\mu_{B}}\left(\widehat{x}_{W}^{p u b l i c}\right)^{2}+\frac{\tau w_{W}(r+\delta)}{\mu_{B}} \widehat{x}_{W}^{p u b l i c}-\left(w_{W}-b\right)(r+\delta)=0
$$

Since $\mu_{B}$, the speed of the public transportation system, is lower than $\mu_{W}$, the speed of cars and since $\frac{\partial \widehat{x}_{k}^{*}}{\partial \mu_{k}}>0$ (see $(22)$ ), it should be clear that $\widehat{x}_{W}^{\text {public }}<\widehat{x}_{W} \equiv \widehat{x}_{W}^{c a r}$. We can therefore write the steady-state value function of this deviant white worker who uses public transportation as:

$$
r U_{W}^{p u b l i c}=\Omega_{W}+b-f_{B}+m(\theta)\left[2 \int_{0}^{\widehat{x}_{W}^{p u b l i c}}\left[E_{W}^{p u b l i c}\left(x, w_{W}\right)-U_{W}^{p u b l i c}\right] d x\right]
$$

Note that this is the most favorable case for an individual white worker who takes public transport since she has a wage of $w_{W}$ but pays the lowest transportation fee $f_{B}$. So if this person prefers to have a car rather than using public transportation, then there does not exist an equilibrium where all white workers use cars. Again, the underlying assumption based on statistical discrimination is that employers do not directly observe the transport 
mode and the location of each worker but they believe that all white workers have cars. The only disadvantage of using public transportation for a deviant white worker is the smaller set of jobs that is available, i.e. $\widehat{x}_{W}^{\text {public }}<\widehat{x}_{W}$. The steady-state value functions of respectively an employed non deviant white worker who has a car and a deviant who uses public transportation are given by:

$$
\begin{array}{r}
r E_{W}^{c a r}\left(x, w_{W}\right)=\Omega_{W}+w_{W}\left(1-\tau \frac{x}{\mu_{W}}\right)-f_{W}-\delta\left[E_{W}^{c a r}\left(x, w_{W}\right)-U_{W}^{c a r}\right] \\
r E_{W}^{p u b l i c}\left(x, w_{W}\right)=\Omega_{W}+w_{W}\left(1-\tau \frac{x}{\mu_{B}}\right)-f_{B}-\delta\left[E_{W}^{p u b l i c}\left(x, w_{W}\right)-U_{W}^{p u b l i c}\right]
\end{array}
$$

The condition that guarantees than whites always prefer a car over public transportation can be written as: $U_{W}^{c a r}>U_{W}^{\text {public }}$. Since $U_{W}^{c a r}$ and $U_{W}^{\text {public }}$ do not depend on $x,(34)$ and (36) can be written as:

$$
\begin{gathered}
{\left[r+2 m(\theta) \widehat{x}_{W}\right] U_{W}^{c a r}=\Omega_{W}+b-f_{W}+2 m(\theta) \int_{0}^{\widehat{x}_{W}} E_{W}^{c a r}\left(x, w_{W}\right) d x} \\
{\left[r+2 m(\theta) \widehat{x}_{W}^{p u b l i c}\right] U_{W}^{p u b l i c}=\Omega_{W}+b-f_{B}+2 m(\theta) \int_{0}^{\widehat{x}_{W}^{p u b l i c}} E_{W}^{p u b l i c}\left(x, w_{W}\right) d x}
\end{gathered}
$$

Given than $\widehat{x}_{W}>\widehat{x}_{W}^{\text {public }}$ (whites know that if they use cars then $\widehat{x}_{W}>\widehat{x}_{W}^{\text {public }}$ ), we have: $r+$ $2 m(\theta) \widehat{x}_{W}>r+2 m(\theta) \widehat{x}_{W}^{\text {public }}$. As a result, using (39) and (40), the condition $U^{\text {car }}>U^{\text {public }}$ can be written as:

$$
2 m(\theta)\left[\int_{0}^{\widehat{x}_{W}} E_{W}^{c a r}\left(x, w_{W}\right) d x-\int_{0}^{\widehat{x}_{W}^{\text {public }}} E_{W}^{\text {public }}\left(x, w_{W}\right) d x\right]>f_{W}-f_{B}
$$

Using a similar argument as in (30), we can write

$$
\int_{0}^{\widehat{x}_{k}} E_{k}\left(x, w_{k}\right) d x=\widehat{x}_{k} E_{k}\left(\widehat{x}_{k} / 2\right)
$$

which we use to write (39) and (40) as:

$$
\begin{aligned}
{\left[r+2 m(\theta) \widehat{x}_{W}\right] U_{W}^{c a r} } & =\Omega_{W}+b-f_{W}+2 m(\theta) \widehat{x}_{W} E_{W}^{c a r}\left(\widehat{x}_{W} / 2\right) \\
{\left[r+2 m(\theta) \widehat{x}_{W}^{p u b l i c}\right] U_{W}^{\text {public }} } & =\Omega_{W}+b-f_{B}+2 m(\theta) \widehat{x}_{W}^{\text {public }} E_{W}^{\text {public }}\left(\widehat{x}_{W}^{\text {public }} / 2\right)
\end{aligned}
$$

Equation (42) also implies that (41) can be written as

$$
2 m(\theta)\left[\widehat{x}_{W} E_{W}^{c a r}\left(\widehat{x}_{W} / 2\right)-\widehat{x}_{W}^{\text {public }} E_{W}^{\text {public }}\left(\widehat{x}_{W}^{\text {public }} / 2\right)\right]>f_{W}-f_{B}
$$


If we now evaluate $E_{W}^{c a r}\left(x, w_{W}\right)$ and $E_{W}^{p u b l i c}\left(x, w_{W}\right)$, defined by (37) and (38), at $x=\widehat{x}_{k} / 2$, we obtain:

$$
\begin{gathered}
(r+\delta) E_{W}^{c a r}\left(\widehat{x}_{W} / 2, w_{W}\right)=\Omega_{W}+w_{W}\left(1-\tau \frac{\widehat{x}_{W} / 2}{\mu_{W}}\right)-f_{W}+\delta U_{W}^{c a r} \\
(r+\delta) E_{W}^{p u b l i c}\left(\widehat{x}_{W}^{\text {public }} / 2, w_{W}\right)=\Omega_{W}+w_{W}\left(1-\tau \frac{\widehat{x}_{W}^{\text {public }} / 2}{\mu_{B}}\right)-f_{B}+\delta U_{W}^{\text {public }}
\end{gathered}
$$

Using (43) and (44), these two equations are equivalent to:

$$
\begin{aligned}
r E_{W}^{c a r}\left(\widehat{x}_{W} / 2, w_{W}\right) & =\Omega_{W}-f_{W}+\frac{\delta b+\left[r+2 m(\theta) \widehat{x}_{W}\right] w_{W}\left(1-\tau \frac{\widehat{x}_{W} / 2}{\mu_{W}}\right)}{\left[r+\delta+2 m(\theta) \widehat{x}_{W}\right]} \\
r E_{W}^{\text {public }}\left(\widehat{x}_{W}^{\text {public }} / 2, w_{W}\right) & =\Omega_{W}-f_{B}+\frac{\delta b+\left[r+2 m(\theta) \widehat{x}_{W}^{\text {public }}\right] w_{W}\left(1-\tau \frac{\widehat{x}_{W}^{\text {public }} / 2}{\mu_{B}}\right)}{\left[r+\delta+2 m(\theta) \widehat{x}_{W}^{\text {public }}\right]}
\end{aligned}
$$

Plugging the above two equations in (45), leads to:

$$
\begin{aligned}
& \Omega_{W}\left(\widehat{x}_{W}-\widehat{x}_{W}^{\text {public }}\right)+\frac{\widehat{x}_{W}\left[\delta b+w_{W}\left(1-\tau \frac{\widehat{x}_{W}}{2 \mu_{W}}\right)\left(r+2 m(\theta) \widehat{x}_{W}\right)\right]}{r+\delta+2 m(\theta) \widehat{x}_{W}} \\
& -\frac{\widehat{x}_{W}^{\text {public }}\left[\delta b+w_{W}\left(1-\tau \frac{\widehat{x}_{W}^{\text {public }}}{2 \mu_{B}}\right)\left(r+2 m(\theta) \widehat{x}_{W}^{\text {public }}\right)\right]}{r+\delta+2 m(\theta) \widehat{x}_{W}^{\text {public }}} \\
> & \frac{r\left(f_{W}-f_{B}\right)}{2 m(\theta)}+\widehat{x}_{W} f_{W}-\widehat{x}_{W}^{\text {public }} f_{B}
\end{aligned}
$$

Observe that

$$
u_{W}^{c a r}=\frac{\delta}{r+\delta+2 m(\theta) \widehat{x}_{W}}
$$

and

$$
u_{W}^{\text {public }}=\frac{\delta}{r+\delta+2 m(\theta) \widehat{x}_{W}^{\text {public }}}
$$

are the probabilities to be unemployed for respectively a non-deviant white who takes the car and a deviant white worker who takes public transportation. Note that $u_{W}^{c a r}<u_{W}^{\text {public }}$ since $\widehat{x}_{W}>\widehat{x}_{W}^{p u b l i c}$. Therefore, (46) can be written as:

$$
\begin{gathered}
\Omega_{W}\left(\widehat{x}_{W}-\widehat{x}_{W}^{\text {public }}\right)+\widehat{x}_{W}\left[u_{W}^{c a r} b+\left(1-u_{W}^{c a r}\right) w_{W}\left(1-\tau \frac{\widehat{x}_{W}}{2 \mu_{W}}\right)\right] \\
-\widehat{x}_{W}^{\text {public }}\left[u_{W}^{\text {public }} b+\left(1-u_{W}^{\text {public }}\right) w_{W}\left(1-\tau \frac{\widehat{x}_{W}^{\text {public }}}{2 \mu_{W}}\right)\right]>\frac{r\left(f_{W}-f_{B}\right)}{2 m(\theta)}+\widehat{x}_{W} f_{W}-\widehat{x}_{W}^{\text {public }} f_{B} .
\end{gathered}
$$


Denote the average income in each case by:

$$
A I_{W}^{c a r}=u_{W}^{c a r} b+\left(1-u_{W}^{c a r}\right) w_{W}\left(1-\tau \frac{\widehat{x}_{W}}{2 \mu_{W}}\right)
$$

and

$$
A I_{W}^{\text {public }}=u_{W}^{p u b l i c} b+\left(1-u_{W}^{p u b l i c}\right) w_{W}\left(1-\tau \frac{\widehat{x}_{W}^{p u b l i c}}{2 \mu_{W}}\right)
$$

As a result, the inequality above reduces to:

$$
\left(\widehat{x}_{W}-\widehat{x}_{W}^{\text {public }}\right) \Omega_{W}+\widehat{x}_{W}\left(A I_{W}^{c a r}-f_{W}\right)-\widehat{x}_{W}^{\text {public }}\left(A I_{W}^{\text {public }}-f_{B}\right)>\frac{r\left(f_{W}-f_{B}\right)}{2 m(\theta)}
$$

which is (27). Observe that we have shown that: $U_{W}^{c a r}>U_{W}^{\text {public }}$, which, using (41), automatically implies that $E_{W}^{c a r}>E_{W}^{\text {public }}$.

\section{Proof of Proposition 1}

Note that $\frac{\partial \widehat{x}_{k}}{\partial \mu_{k}}>0$ (see (32)). Since whites use a faster transport mode than blacks, i.e. $\mu_{W}>\mu_{B}$, this implies that $\widehat{x}_{W}^{*}>\widehat{x}_{B}^{*}$. Furthermore, since we have seen that $\frac{\partial w_{k}}{\partial \widehat{x}_{k}}>0$ (see (19)), this implies that $w_{W}^{*}>w_{B}^{*}$. Finally, it immediately follows from (5) and (6) that $u_{W}^{*}<u_{B}^{*}$. 